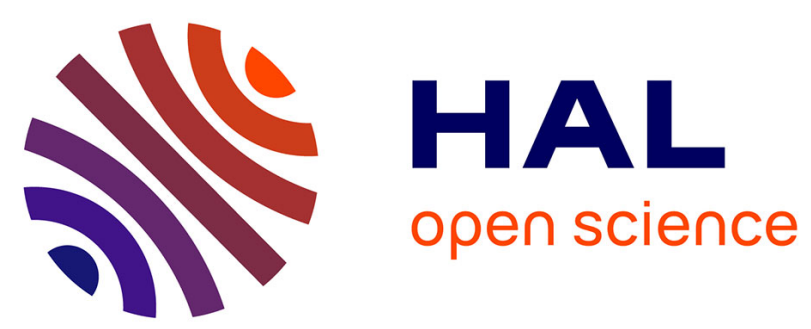

\title{
ONLINE DISTANT LEARNING USING SITUATION-BASED SCENARIOS
}

Fabrice Trillaud, Phuong Thao Pham, Mourad Rabah, Pascal Estraillier, Jamal Malki

\section{- To cite this version:}

Fabrice Trillaud, Phuong Thao Pham, Mourad Rabah, Pascal Estraillier, Jamal Malki. ONLINE DISTANT LEARNING USING SITUATION-BASED SCENARIOS. International Conference on Computer Supported Education (CSEDU 2012), Feb 2012, Porto, Portugal. pp.313-316, 2012. hal00765710

\section{HAL Id: hal-00765710 https://hal.science/hal-00765710}

Submitted on 17 Dec 2012

HAL is a multi-disciplinary open access archive for the deposit and dissemination of scientific research documents, whether they are published or not. The documents may come from teaching and research institutions in France or abroad, or from public or private research centers.
L'archive ouverte pluridisciplinaire HAL, est destinée au dépôt et à la diffusion de documents scientifiques de niveau recherche, publiés ou non, émanant des établissements d'enseignement et de recherche français ou étrangers, des laboratoires publics ou privés. 


\title{
ONLINE DISTANT LEARNING USING SITUATION-BASED SCENARIOS
}

\author{
Fabrice Trillaud, Phuong Thao Pham, Mourad Rabah, Pascal Estraillier and Jamal Malki \\ L3i Laboratory, University of La Rochelle, La Rochelle, France \\ \{fabrice.trillaud, phuong_thao.pp, mourad.rabah, pascal.estraillier, jamal.malki\}@univ-lr.fr
}

\begin{abstract}
Keywords: situation-based model:adaptive scenario:online distant learning:scenario management:scenario execution process

Abstract: $\quad$ This paper is an overview of our work to deal with scenario representation and management model in Online Distant Learning domain. Our approach is based on scenario structuring using the notion of "situation". A "situation" is an elementary building block dividing the interactions between actors into contextual scenes. This pattern not only supports the scenario execution, but also its creation and evolution. After discussing the global methodology to manage ODL applications and introducing the situation-based scenarios, we show how our methodology and situation structuring can be applied to and enhance ODL.
\end{abstract}

\section{INTRODUCTION}

Online Distant Learning (ODL) is now becoming a mature research domain (Lionarakis, 2009). We witness the development of online training applications and the use of generic online meeting applications for training purpose to create online virtual classrooms. But generic interactive applications are not well suited to a training context, and specialized ones can require too much learning time to master (Murphy and Manzanares, 2008)(Kinser, 2003), slowing down their acceptance by the users (Jung et al., 2006)(Pigliapoco et al., 2008). Moreover, users expect new learning possibilities through the use of these applications (Hay et al., 2004).

ODL is not simply an unfolding of a "video conference" or "online meeting". A learning session can be seen as a "scenario" that organizes the educational activities. However, scenario organization for training purpose in online learning is still rarely used or studied. We want to structure and organize learning sessions into scenarios in an effective way. To achieve this, we propose the use of "situations" blocks. Each "situation" is a sequence of interactions between application's actors within a given shared context (Pham et al., 2012). Furthermore, the situation-based scenario uses interactive storytelling techniques as well as consistency management (Pham et al., 2011) in dynamical execution to ensure robustness and interactivity for online learning. It also facilitates the adaptability during the training session and improves the training quality by analyzing feedbacks and results.

We aim to obtain a complete generic situationbased adaptive scenario management system, including authoring tool, execution environment, and scenario evolution control all along its lifecycle, since users are looking for a system that can adapt itself to its context and environment (McKee, 2010). The resulting system has to be accessible for everyone, without requiring particular training or equipment, as these are the main problems associated with the implementation of ODL systems (Cardoso and Bidarra, 2009). This paper gives a quick overview of our situation-based model and details its application to ODL case study.

\section{ODL METHODOLOGY}

Our scenario management system uses a threestep cycle, namely Before (scenario's construction), Throughout (scenario's execution) and After (execution's analysis). Using this cycle, users involved in scenario's lifecycle are given tools and clues to improve it between each execution. This cycle can be applied to other interactive systems with scenariobased execution.

We must at first determine system's actors and their environment. In ODL, we define three different types of real actors: learners, trainers and training organization. Each of them is involved in one or several 
steps of the scenario's lifecycle in ODL, and may take on one or several roles, such as auditor, presenter, moderator and designer. Figure 1 shows how each involved actors and roles steps into this cycle, represented by a three-segment arrow, representing the Before, Throughout and After steps.

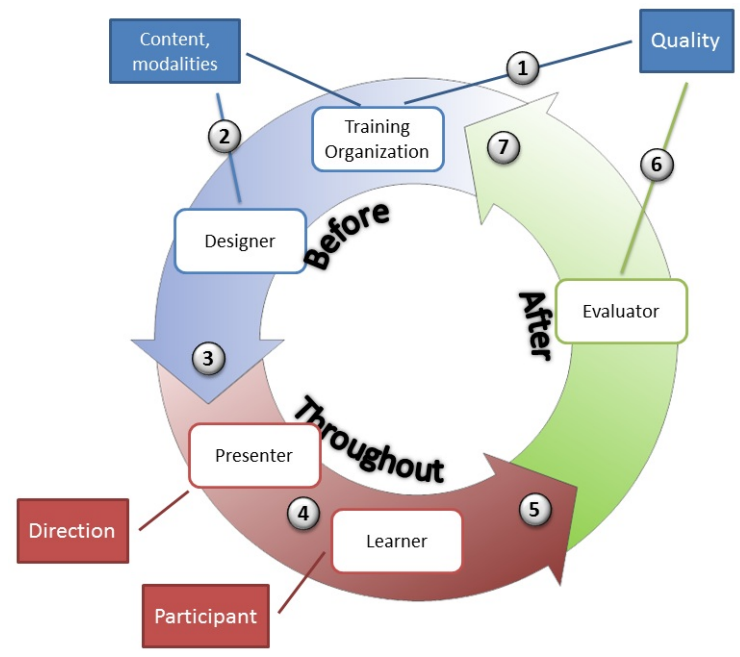

Figure 1: Scenario's lifecycle in ODL

The seven points illustrated in the figure 1 are: the definition of quality standards (1), the definition of the training's content (2), the choice of associated resources (3), the execution of the training session (4), the events recording (5), the events analysis (6) and the feedback to the actors (learners, trainers, and organization) (7).

The "training organization" is responsible for the training's quality: Before the execution, it defines rules and imperatives of the training. The "evaluator", in the After step belongs to the training organization as well. He points out the most meaningful events reported by some observation mechanisms, and dispatches them to the concerned actors in order to improve the training prior to the next execution.

\section{APPLICATION STRUCTURING}

In the interactive domain, story or plot structuring has been studied in many areas, such as games, interactive drama and storytelling (Magerko, 2005)(Mateas and Stern, 2005)(Paul et al., 2011), but also simulation and educational applications. Interactive applications from our point of view always have a scenario defining the interactive environment and tasks that actors have to do. In order to provide a story model, we propose the notion of "situation" (Pham et al., 2012). The situations are the narrative basic blocks that fa- cilitate the story planning and management by characterizing and confining the interactions.

A situation is a sequence of interactions between two or more actors in a precise context to achieve a predictive objective. It is characterized by the following set of elements, illustrated in figure 2 .

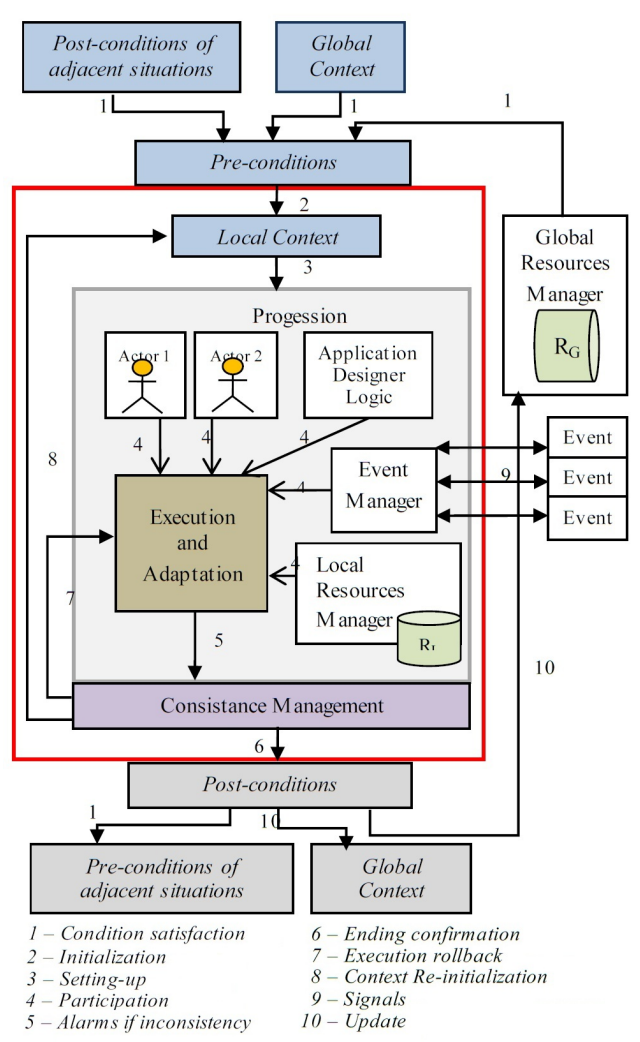

Figure 2: Situation model

- Pre-conditions: set of conditions that must be satisfied to enter the situation.

- Post-conditions: set of conditions or results that must be completed in order to leave the situation.

- Progression: presents a frame where actors behave and interact using local resources and launching different tasks according to their objectives. Situation progression involves:

- Actors: real (human, physical) or virtual (system components, agents, non-player character).

- Application's designer logic: what the system is allowed/supposed to do. It will orient the actors' activities and tasks along the progression.

- Event management: deals with the incoming/outgoing events from/to the external world or others simultaneous situations. 
- Resources managers: system's actors responsible for resources access and utilization with respect to actors' needs. Resources can be local or global.

- Consistency management: mechanisms handling actor's inconsistency (Pham et al., 2011).

We distinguish 3 kinds of situations: elementary situations (basic situations introduced above), composite situations (abstract situations that recursively include other situations) and usable situations or parameter situations (ready-to-use situations, predesigned and instantiated with common parameters) (Pham et al., 2012).

An application scenario is finally represented as an ordered sequence or directed graph of all possible situations that can happen between actors.

\section{APPLICATION TO ODL}

We applied our proposition to our Online Distant Learning framework. This framework deals with activities structuring in distributed virtual classroom. We use our situation-based structuring to organize class learning activities. We have first identified the corresponding situations and build the situations library. Then we have defined the scenario situation graph that allowed us to assess the methodology feasibility and perform adaptivity tests.

\subsection{Building scenarios using situations}

Our methodology of scenario specification is based on the decomposition of pedagogic activities encountered in a classical face-to-face classroom. A classical course is regularly unfolded into several activities, such as lesson lecture, exercise working, going to the blackboard, examinations... Each activity consists of a set of actions and interactions between the trainer and the learners using appropriate content and resources.

This lecture structuring into activities in a faceto-face class justifies the situations construction in our work. Our concept of situations is well suited to represent learning relatively independent activities in ODL because these scenario structuring blocs allow actions and interactions contextualization.

Generally, the situations library is determined by application designers from the development point of view. They have to satisfy reusability and generalization. The ODL sessions are then created from the situations library by the course designer or the trainer himself. The scenario structuring is thus based on the main activities and steps in a real classroom.
The elementary situations defined for our virtual classroom are: Presentation, Moderation, Discussion, Individual working, Collaborative working, Browser sharing, Survey and Grade. We also defined the composite situations: Lesson lecture, Class working, Going to the blackboard and Evaluation; and the usable situations: Group work and Examination. The figure 3 gives three examples of situations.

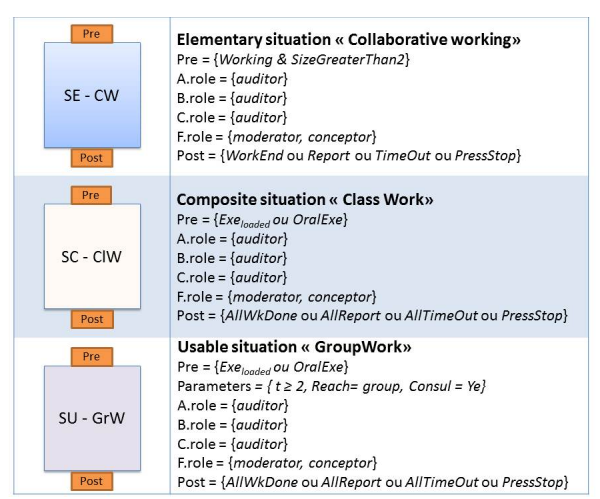

Figure 3: Three kinds of situations

To validate our proposition, we defined a standard typical scenario structured with situations for a lesson session. The basic scenario contains the following steps: Start of the lesson, Classwork, Going to the Blackboard, Discussion and Survey. This five-step scenario is "converted" into situations and organized into a graph, as shown in the figure 4.

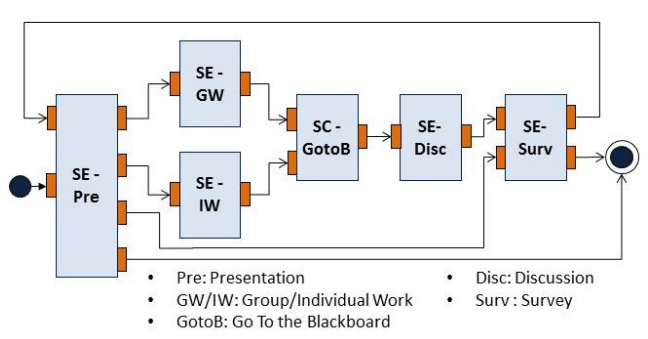

Figure 4: Example scenario.

Transitions between situations are triggered by various events during the application execution, such as publishing an exercise, designating a learner to go to the virtual board, publishing a survey and so on.

\subsection{Advanced scenario management}

The course scenario is defined before the course begins. It may have some weak points if it has rigid and static structure. Indeed, once the scenario is created and the course begins, it cannot be modified; class activities can neither be added nor deleted. In real class, the trainer may plan out his course scenario in the $b e$ fore step, but he is not certain that he will follow it 
exactly as he intended initially. Therefore, although the scenario is predetermined, it must be adaptive to be easily modified or customized during the course. Our approach gives this freedom to the trainer by allowing the trainer to interchange situation blocks.

We could also mention the adaptation resulting from consistency management, external events or other types of adaptation. These are further discussed in other papers. Please see our case study for examples of adaptation, scenario's execution, and more details about the architecture and the adaptive scenario management (Trillaud et al., 2011) ${ }^{1}$.

\section{CONCLUSIONS}

We have presented the methodology overview of our situation-based adaptive scenario management system. The situation model is used not only to construct scenarios, but also to improve them through the 3-steps lifecycle, namely before, throughout and after. The situations support the scenario creation before system execution beginning; the automatic navigation, dynamic adaption and consistency management in the throughout step; and scenario improvement after its execution. The notion of "situation" is proposed to be a reusable model to all types of interactive applications for which the execution can be organized as a scenario. This methodology allows us to build robust system architecture.

Since the Online Distant Learning is organized as sequence of learning activities, it is well suited to situation-based structuring. We have categorized ODL actors with their different roles; these roles can be changed during training session. Form the identified activities, we have defined the library of situations that is used to structure lessons in ODL. This may allow best interactive online training, compared to most existing online training or meeting applications: the trainer gets a permanent feedback on the training execution; keeps control over the scenario and can adapt it in a flexible way (a comparative study has been carried out and will be the subject of upcoming publications (Trillaud et al., 2011)).

Finally, we gave a glimpse of what the scenario adaptation can be within situation-based scenario, but there is much more to say about it, through tracks analysis, consistency management or interactive storytelling. This will be covered in future publications.

We are now completing our works through several aspects: development of the authoring system

\footnotetext{
${ }^{1}$ http://foad-13i.univ-lr.fr for more informations about our ODL project
}

supporting scenario creation and improvement, use of traces analysis to support the scenario's lifecycle, complete integration of scenario management within our ODL framework, and live tests with real online trainers and learners. Our final aim is to estimate and prove the performance and pertinence of our scenario management methodology for different scenarios in various interactive applications fields.

\section{REFERENCES}

Cardoso, V. and Bidarra, J. (2009). Open and Distance Learning: Does IT (Still) Matter? E-Learning, pages $1-6$.

Hay, A., Hodgkinson, M., Peltier, J. W., and Drago, W. A. (2004). Interaction and virtual learning. Strategic Change, 13(4): 193-204.

Jung, M.-1., Loria, K., Mostaghel, R., and Saha, P. (2006). E-Learning : Investigating University Student's Acceptance of Technology. E-learning, (2001):1-9.

Kinser, K. (2003). Diversity Within the Virtual Classroom. New Directions for Institutional Research, 2003(118):69-77.

Lionarakis, A. (2009). The theory of distance education and its complexity. E-Learning, pages 1-7.

Magerko, B. (2005). Story Representation and Interactive Drama. Artificial Intelligence, pages 87-92.

Mateas, M. and Stern, A. (2005). Structuring Content in the Façade Interactive Drama Architecture. In Proceedings of Artificial Intelligence and Interactive Digital Entertainment, volume 3, pages 93-98.

McKee, T. (2010). Thirty years of distance education: Personal reflections. The International Review of Research in Open and Distance Learning, 11(2):100.

Murphy, E. and Manzanares, M. A. R. (2008). Contradictions between the virtual and physical high school classroom: A third-generation Activity Theory perspective. British Journal of Educational Technology, 39(6):1061-1072.

Paul, R., Charles, D., McNeill, M., and D, M. (2011). Adaptive Storytelling and Story Repair in a Dynamic Environment. The Fourth International Conference on Interactive Digital Storytelling ICIDS 2011.

Pham, P. T., Estraillier, P., and Rabah, M. (2012). Situationbased Scenario for Interactive Applications : Solution to Handle the Misunderstanding in Interaction, report 13i-aspic-20120120-1.

Pham, P. T., Rabah, M., and Estraillier, P. (2011). Handling the Misunderstanding in Interactions : Definition and Solution. The Annual International Conference on Software Engineering \& Applications 2011.

Pigliapoco, E., Torrisi, G., Messina, M., and Bogliolo, A. (2008). LoL Classroom: A Virtual University Classroom Based on Enhanced Chats. European Journal of Open, Distance and E-Learning, Vol. II.

Trillaud, F., Malki, J., and Estraillier, P. (2011). Going to the Blackboard: a case study. Online Educa Berlin. 